\title{
USE OF VASCULARIZED ILIAC CREST WITH INTERNAL OBLIQUE MUSCLE FLAP FOR MANDIBLE RECONSTRUCTION
}

\author{
M. MARANZANO, M.D., ${ }^{1 *}$ G. FRESCHI, M.D., ${ }^{1}$ A. ATZEI, M.D., ${ }^{2}$ and A.M. MIOTTI, M.D. ${ }^{1}$
}

\begin{abstract}
In the last decade, immediate reconstruction of maxillary bones following extensive trauma, large oncological defects, or late effects of radiation therapy has proved to be a reliable morpho-functional reconstruction technique. Use of the vascularized iliac crest with an internal oblique flap has become our flap of choice for mandible reconstruction when there is no need for overlying facial skin or oral sphincter reconstruction, and for bone segments within $6-15 \mathrm{~cm}$ of length. The advantages of this composite bone flap are the large and resizable bone stock avaliable, the quality of bone transferred with an optimal height, depth, and contour of bone to mantain a good facial profile, and the possibility to reconstruct properly the oral lining, with a portion of the internal oblique muscle flap raised with the same pedicle that epithelializes during the healing stages. We present the experience of the Department of Maxillofacial Surgery of "S. Maria della Misericordia" Regional Hospital in Udine, Italy. (c) 2005 Wiley-Liss, Inc. Microsurgery 25:299-304, 2005.
\end{abstract}

Immediate or delayed reconstructions of maxillary bones after extensive trauma or large oncological resections, expecially the mandible, are nowadays considered reliable, with good immediate and long-term relults. When the treatment plan arranged by the clinical team and the patient is to proceed with mandible reconstruction, many opportunities are available using free tissue transfer techniques. All these techniques have to provide not only for mandibular recontruction but for adequate rebuilding of the internal oral cavity. If the length of mandibular bone to be reconstructed is between $6-15 \mathrm{~cm}$, and the treatment plan requires internal soft-tissue reconstruction only, with no need for overlying facial skin or oral sphincter reconstruction, use of the vascularized iliac crest with an internal oblique muscle flap has to be considered one of the first choices.

The vascularized iliac crest with an internal oblique muscle flap was popularized by Urken et al. in $1998,{ }^{1}$ when they reported few failures and low donor-site morbidity in their series. The use of the internal oblique muscle had been considered inferior in outcome if compared with the composite fibula flap described by Hidalgo and Rekow in $1995 .^{2}$

The vascularized iliac crest with an internal oblique muscle flap is unique for the advantages it can offer in terms of quality and quantity of bone, contouring of the mandible, and kinds of internal oral soft-tissue reconstruction. The portion of the internal oblique muscle lines the oral cavity and becomes epithelialized in such a

${ }^{1}$ Department of Maxillofacial Surgery, Regional Hospital "S. Maria della Misericordia," Udine, Italy

${ }^{2}$ Department of Hand Surgery, University Hospital "G.B. Rossi," Verona, Italy *Correspondence to: Mr. Massimo Maranzano, Department of Maxillofacial Surgery, Regional Hospital "S. Maria della Misericordia," 15 S. Maria della Misericordia Sq., 33100 Udine, Italy. E-mail: maranzano.massimo@aoud. sanita.fvg.it

Received 28 February 2005; Accepted 8 March 2005

Published online 10 June 2005 in Wiley InterScience (www.interscience. wiley.com). DOI: 10.1002/micr.20129 way as to provide an excellent mucosal enviroment. The quality of bone is as good as the internal lining, providing good support for an implant-retention prosthesis.

The aim of this study is to report the experience of the Maxillofacial Unit of "S. Maria della Misericordia" Regional Trust with the vascularized iliac crest with internal oblique muscle flaps for mandibular reconstruction.

\section{PATIENTS AND METHODS}

The clinical notes of 21 consecutive patients who had had a recontruction procedure using a vascularized iliac crest with an internal oblique muscle flap reconstruction procedure were analyzed from June 2001-December 2003. The diagnosis, Tumor Node Metastasis (TNM) classification, and type of defect were recorded for each patient.

Of these patients, 6 had been dismissed because they had had a maxillary reconstruction using this type of composite flap.

The number of patients enrolled for this study on mandible reconstruction is therefore 15 (Table 1).

All patients had had bone involvement and can be classified as T4 following the TNM classification (Table 1).

The type of defect was classified by looking at the amout of mandible to be recontructed as follows (Fig.1):

1. Ramus of the mandible \pm condyle (type 1 );

2. Body of the mandible (type 2);

3 . Body and ramus of the mandible \pm condyle (type 3 );

4. Mandibular symphisis (type 4); and

5. Bilateral body of the mandible + symphisis (type 5 ).

Our surgical technique was basically the one described by Urken et al. in $1998^{3-14}$ with the superolateral approach, and the modification of this tecnique 
Table 1. Summary of Main Data of Complete Group of Patients $(n=15)^{\star}$

\begin{tabular}{|c|c|c|c|c|}
\hline No. & Diagnosis & TNM & Defect & Outcome \\
\hline 1 & Osteonecrosis & $\mathrm{N} / \mathrm{A}$ & Type 2 & Alive \\
\hline 2 & SCC & T4N2 & Type 2 & $\begin{array}{l}\text { LR, } 10 \text { months; second flap; } \\
\text { died, HA } 18 \text { months }\end{array}$ \\
\hline 3 & SCC & T4NO & Type 2 & Alive \\
\hline 4 & Osteonecrosis & $\mathrm{N} / \mathrm{A}$ & Type 3 & Alive \\
\hline 5 & SCC & T4N1 & Type 4 & Alive \\
\hline 6 & SCC & T4NO & Type 3 & Alive \\
\hline 7 & SCC & T4NO & Type 4 & Alive \\
\hline 8 & Osteonecrosis & $\mathrm{N} / \mathrm{A}$ & Type 4 & Alive \\
\hline 9 & SCC & T4N1 & Type 5 & $\begin{array}{l}\text { Died, HA } 20 \text { days } \\
\text { after operation }\end{array}$ \\
\hline 10 & SCC & T4NO & Type 2 & Alive \\
\hline 11 & SCC & T4NO & Type 2 & Alive \\
\hline 12 & Ameloblastoma & $N / A$ & Type 3 & Alive \\
\hline 13 & SCC & T4N1 & Type 5 & Alive \\
\hline 14 & SCC & T4NO & Type 3 & Alive \\
\hline 15 & Ameloblastoma & $\mathrm{N} / \mathrm{A}$ & Type 3 & Alive \\
\hline
\end{tabular}

${ }^{*} S C C$ squamous cell carcinoma; LR local recurrence; HA heart attack; N/A net applicable.

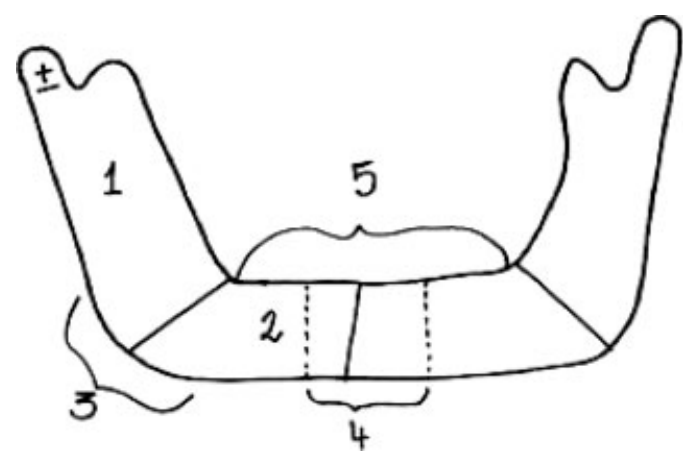

Figure 1. Classification of mandible defects.

described by Vaughan ${ }^{15}$ with the infero-medial approach, depending on the quantity of internal oblique muscle needed.

In all treated cases, the flap had been raised ipsilaterlal to the defect site except for type 4 and 5 (Figs. 1-3) mandibular defects, where there is no significance to the donor side.

There have been two different approaches to type 3 (body, ramus. and mandibular angle). Specifically, we used two different kinds of bone design. In the first design, we harvested the iliac bone using the anterior superior iliac spine (ASIS) in order to reconstruct the Lshaped new mandible with no osteotomies (Figs. 4-8); in the latter, we did not include the ASIS in the flap, and we performed bone osteotomies to reshape the new mandible (Figs. 5, 9-10).

The amount of internal oblique muscle harvested varied, among the patients treated (Table 2), between $15-120 \mathrm{~cm}^{2}$. The muscle had always been well-vascu-

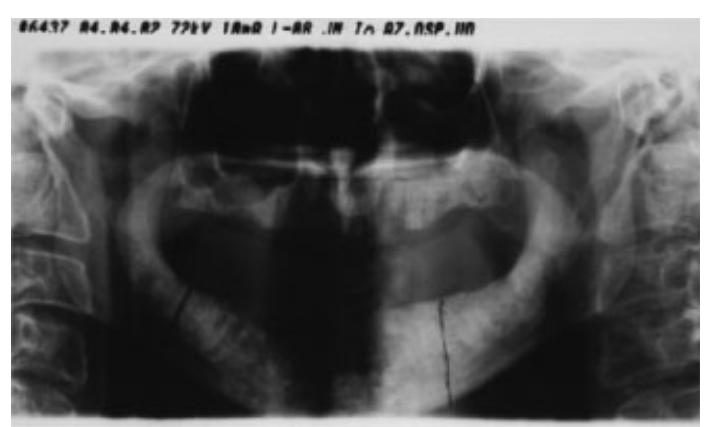

Figure 2. Case 1: bilateral body + symphysis.

larized on the ascending branch of the DICA/V. In the oral cavity, the muscle becomes fibromucotized (Fig. 11) and offers a good layer for implant placement. No trismus was ever observed in our patients.

Particular care had been used for the donor-site closure. A Marlex mesh in two layers was used in all patients. No abdominal wall weakness has developed in these patients (Figs. 12, 13).

Neck dissections were carried out in 10 of 15 patients, while the other 5 patients were affected by nonmalignant disease or had had secondary reconstruction.

A detailed assesment of surgical complications was carried out.

Two stages of osteointegrated implants had been positioned in 10 of 13 patients who underwent mandibular reconstruction with a DICA flap. Implant positioning had been performed under general anesthesia in all patients, as well as second-stage surgery for healing screws positioning and soft-tissue redrapping around implants (Fig. 14). Overall, we positioned 


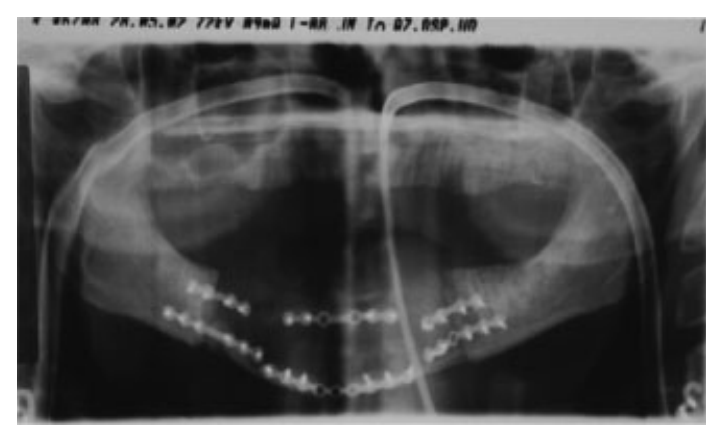

Figure 3. Case 1: bilateral body + symphysis.

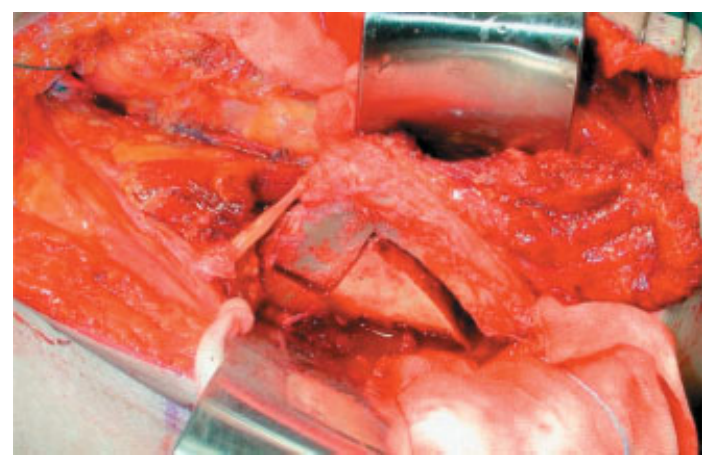

Figure 4. DCIA, including ASIS. [Color figure can be viewed in the online issue, which is available at www.interscience.wiley.com.]

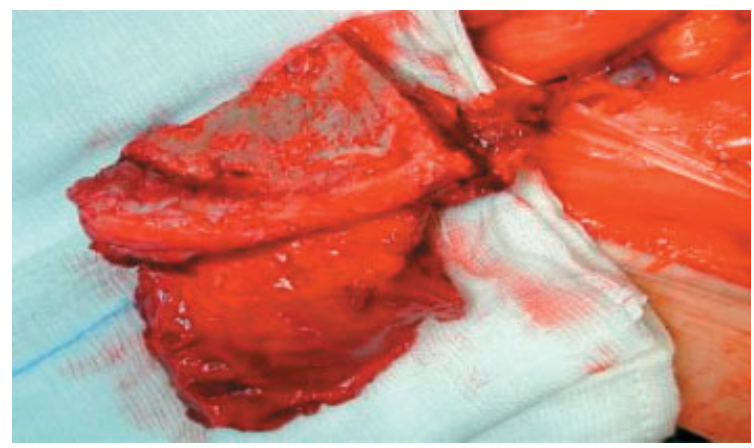

Figure 5. DCIA, not including ASIS. [Color figure can be viewed in the online issue, which is available at www.interscience.wiley.com.]

48 fixtures with a minimum of three and a maximum of six two-stage osteointegrated implants ${ }^{9,14,16-20}$ for every patient. No implant loss was reported in our series.

\section{RESULTS}

Fifteen consecutive patients had a mandibular resection reconstructed with a vascularized iliac crest with an internal oblique flap. There were 10 males and 5 females, with a mean age of 54 years (range, 32-64). Three patients were operated upon for os-

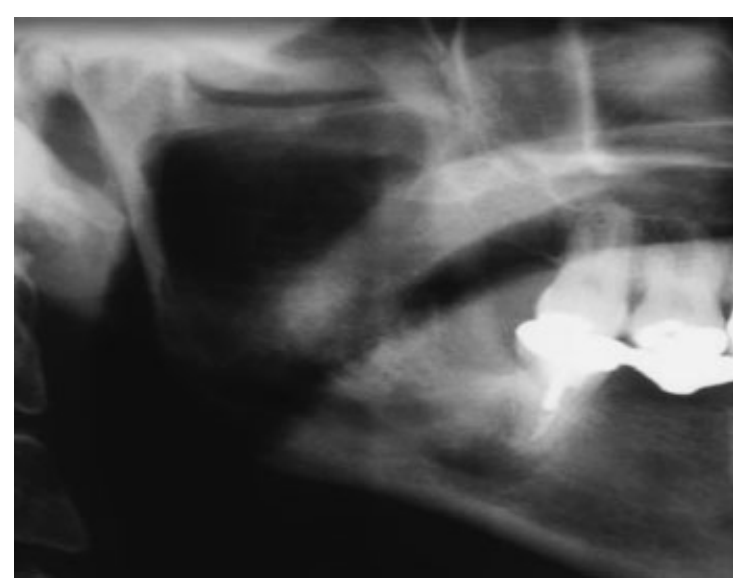

Figure 6. Case 3: condyle + ramus + body.

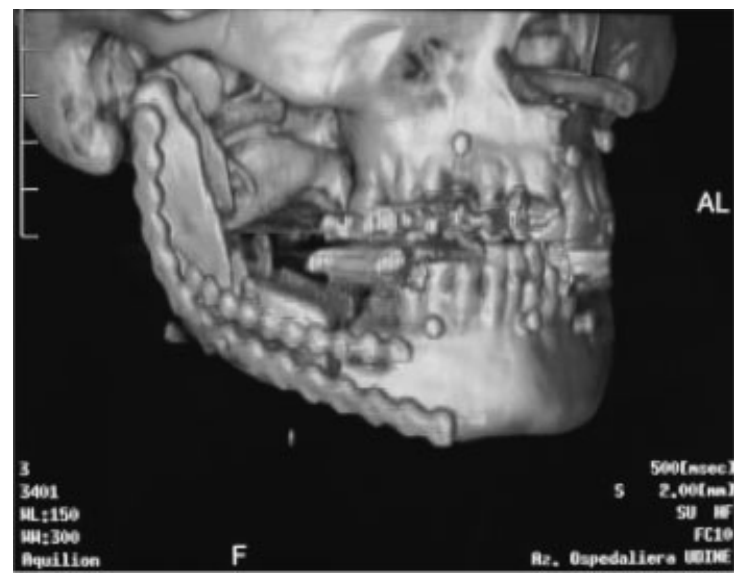

Figure 7. Case 3: condyle + ramus + body.

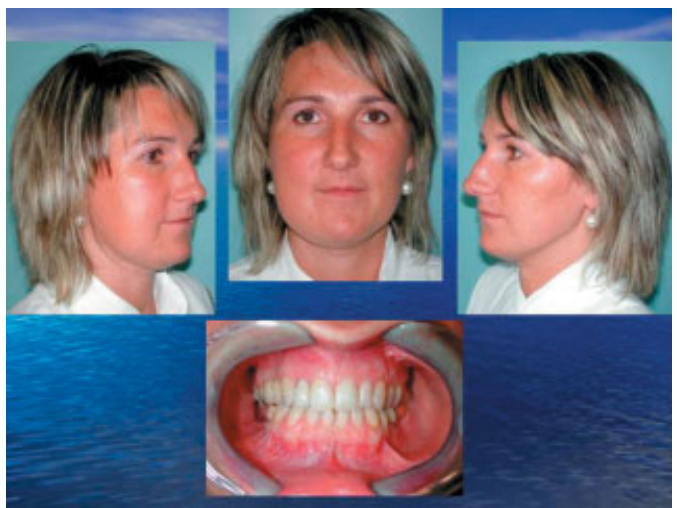

Figure 8. Final result. Type 3 reconstruction. [Color figure can be viewed in the online issue, which is available at www.interscience. wiley.com.]

teoradionecrosis of the mandible, while two had a nonmalignant disease, and the rest were treated for disease that required ablation with immediate reconstruction. 


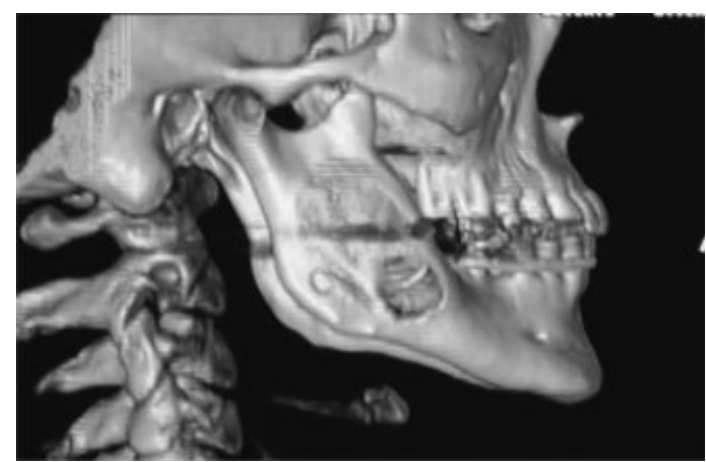

Figure 9. Case 2: ramus + body.

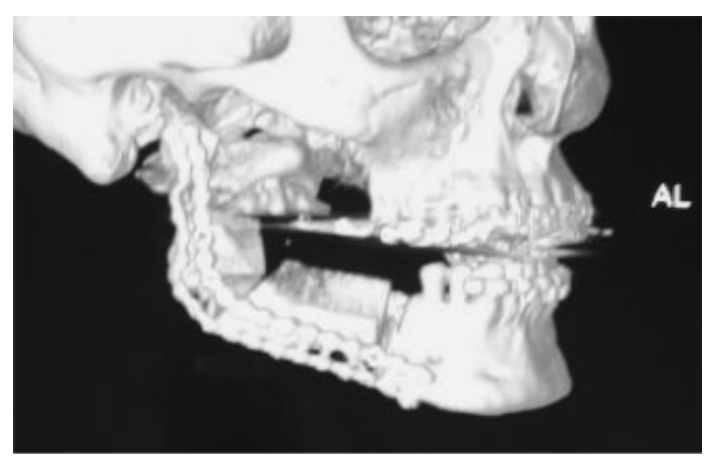

Figure 10. Case 2: ramus + body.

Table 1. Summary of Main Data of Complete Group of Patients $(n=15)^{\star}$

\begin{tabular}{|c|c|c|c|c|}
\hline No. & Diagnosis & TNM & Defect & Outcome \\
\hline 1 & Osteonecrosis & $\mathrm{N} / \mathrm{A}$ & Type 2 & Alive \\
\hline 2 & SCC & T4N2 & Type 2 & $\begin{array}{l}\text { LR, } 10 \text { months; second flap; } \\
\text { died, HA } 18 \text { months }\end{array}$ \\
\hline 3 & SCC & T4NO & Type 2 & Alive \\
\hline 4 & Osteonecrosis & $\mathrm{N} / \mathrm{A}$ & Type 3 & Alive \\
\hline 5 & SCC & T4N1 & Type 4 & Alive \\
\hline 6 & SCC & T4NO & Type 3 & Alive \\
\hline 7 & SCC & T4NO & Type 4 & Alive \\
\hline 8 & Osteonecrosis & $\mathrm{N} / \mathrm{A}$ & Type 4 & Alive \\
\hline 9 & SCC & T4N1 & Type 5 & $\begin{array}{l}\text { Died, HA } 20 \text { days } \\
\text { after operation }\end{array}$ \\
\hline 10 & SCC & T4NO & Type 2 & Alive \\
\hline 11 & SCC & T4NO & Type 2 & Alive \\
\hline 12 & Ameloblastoma & $\mathrm{N} / \mathrm{A}$ & Type 3 & Alive \\
\hline 13 & SCC & T4N1 & Type 5 & Alive \\
\hline 14 & SCC & T4NO & Type 3 & Alive \\
\hline 15 & Ameloblastoma & $\mathrm{N} / \mathrm{A}$ & Type 3 & Alive \\
\hline
\end{tabular}

Two patients died from a heart attack, the former 20 days after the operation, and the latter 18 months later, after a local recurrence within 10 months for which she was operated upon and reconstructed with another free flap.

One flap was lost after 9 months because of a serious oral infection and the developement of an orocervical fistula near the flap that led to an infection of the flap pedicle; this particular patient had had high-dose radiotherapy postoperatively. Subsequently he had had an operation for the fistula and had been reconstructed with a pedicled myocutaneous flap.

No vein graft was necessary in any of our series.

No implant loss occurred in our series of 48 positioned fixtures.

\section{DISCUSSION}

The use of the vascularized iliac crest with an internal oblique flap has become the first flap of choice for mandibular reconstruction when the bony defect is between $6-15 \mathrm{~cm}$, and the treatment plan requires internal soft-tissue reconstruction only, with no need for overlying facial skin or oral sphincter reconstruction in the Department of Maxillofacial Surgery of the Regional Hospital "S. Maria della Misericordia."

The most important finding from our series is the oral and facial rehabilitation that all patients acheived. All patients had a satisfactory result, both intraorally and aesthetically. Some of them started with our implant-retained prosthesis protocol (10 patients), but some (3 patients) had satisfactory results without needing a prosthesis, or had successful oral and facial rehabilitation.

This particular composite flap provides a better base for oral and dental rehabilitation than the one that can be offered by other kind of reconstructions. Fibular flaps provide adrquate length of bone even for segments longer than $15 \mathrm{~cm}$, but fail to provide an 


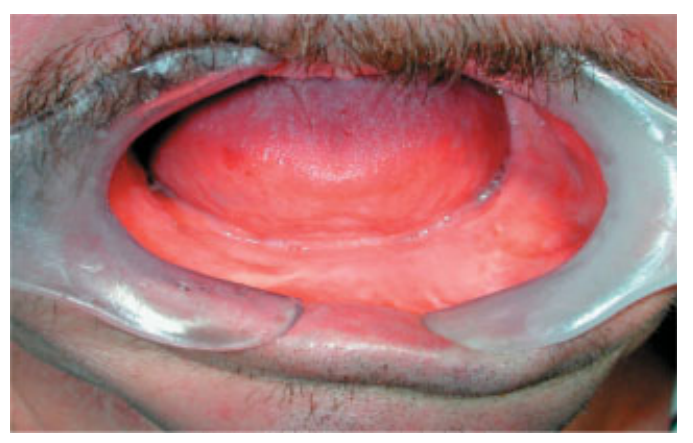

Figure 11. Case 1: bilateral body + symphysis. [Color figure can be viewed in the online issue, which is available at www.interscience. wiley.com.]

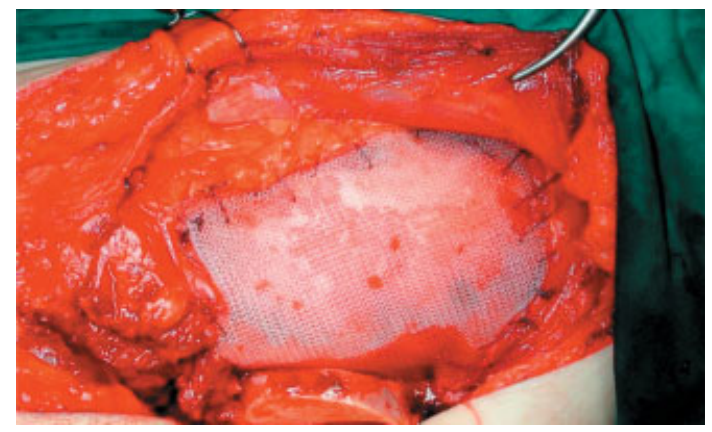

Figure 12. Marlex mesh, first folder. [Color figure can be viewed in the online issue, which is available at www.interscience.wiley.com.]

adequate height of bone to retain properly dental implants without using complementary techniques such as double-barreled fibula flaps or distraction osteogenesis, which add more risk and complexity to the reconstructive procedure. ${ }^{21}$ Moreover, the skin island does not fit well in the oral mucosa and does not offer the same quality of lining and interface for a implant-retained prostetic rehabilitation. It takes considerable flap revision to optimize this interface, with an inevitable result in additional scarring and fibrosis, which can significantly alter the oral tissues. This is also the problem with the composite scapular flap, which has the advantage of better bone qualtity than the composite fibula flap and offers the possibility of raising multiple flaps on a single pedicle. ${ }^{21,22}$ The composite radial forearm flap is not adequate for the quality and quantity of bone it can supply, and in our opinion, it must be considered a second choice for mandible reconstruction. ${ }^{23}$

The vascularized iliac crest with an internal oblique muscle flap provides the best bone source, either for mandible reconstruction in terms of quality, quantity, and aesthetic contouring of the face, or as a unique oral mucosal lining ideal for the implant-soft tissue interface. Microsurgical free flap techniques should be routinely

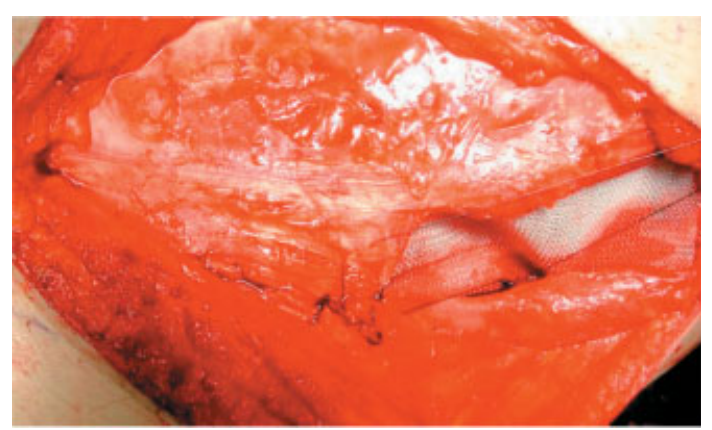

Figure 13. Marlex mesh, second folder. [Color figure can be viewed in the online issue, which is available at www.interscience.wiley. com.]

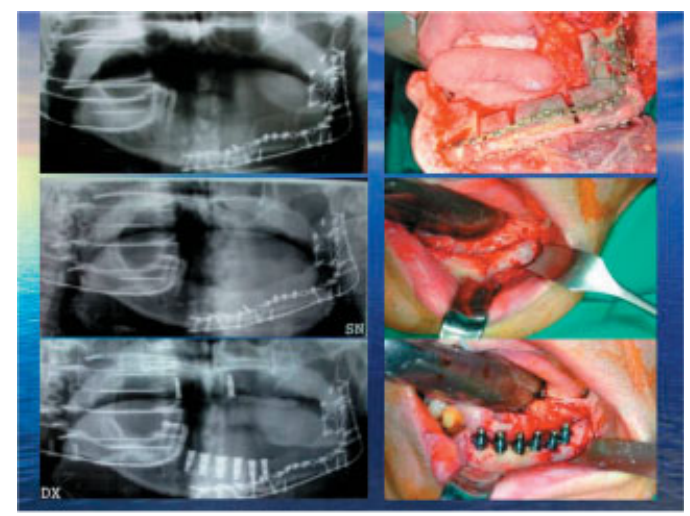

Figure 14. Follow-up of bone reconstruction. [Color figure can be viewed in the online issue, which is available at www.interscience. wiley.com.]

used in head and neck reconstruction, and this particular flap must be considered our first choice for maxillary bones reconstruction.

\section{REFERENCES}

1. Urken ML, Vickery C, Weinberg H, Buchbinder D, Lawson W, Biller HF. The internal oblique-iliac crest osseomyocutaneous free flap in oromandibular reconstruction. Report of 20 cases. Arch Otolaryngol Head Neck Surg 1989;115:339-349.

2. Genden EM, Wallace D, Buchbinder D, Okay D, Urken ML. Iliac crest internal oblique osteomusculocutaneous free flap reconstruction of the postablative palatomaxillary defect. Arch Otolaryngol Head Neck Surg 2001;127:854-861.

3. Brown JS. Deep circumflex iliac artery free flap with internal oblique muscle as a new method of immediate reconstruction of maxillectomy defect. Head Neck 1996;18:412-421.

4. Tamura H, Sasaki K, Watahiki R. Primary insertion of implants in the zygomatic bone following subtotal maxillectomy. Bull Tokyo Dent Coll 2000;41:21-24.

5. Taylor GI. Reconstruction of the mandible with free composite iliac bone grafts. Ann Plast Surg 1982;9:361-376.

6. Cordeiro PG, Santamaria E, Kraus DH, Strong EW, Shah JP. Reconstruction of total maxillectomy defects with preservation of the orbital contents. Plast Reconstr Surg 1998;102:18741887. 
7. Villaret DB, Futran NA. The indications and outcomes in the use of osteocutaneous radial forearm free flap. Head Neck 2003;25: 475-481.

8. Vinzenz KG, Holle J, Wuringer E, Kulenkampff KJ. Prefabrication of combined scapula flaps for microsurgical reconstruction in oro-maxillofacial defects: a new method. J Craniomaxillofac Surg 1996;24:214-223.

9. Kelly CP, Moreira-Gonzalez A, Ali MA, Topf J, Persiani RJ, Jackson IT, Wiens J. Vascular iliac crest with inner table of the ilium as an option in maxillary reconstruction. J Craniofac Surg 2004;15:23-28. [erratum in J Craniofac Surg 2004;15:705].

10. Hidalgo DA, Pusic AL. Free-flap mandibular reconstruction: a 10year follow-up study. Plast Reconstr Surg 2002;110:438-501.

11. Chang YM, Coskunfirat OK, Wei FC, Tsai CY, Lin HN. Maxillary reconstruction with a fibula osteoseptocutaneous free flap and simultaneous insertion of osseointegrated dental implants. Plast Reconstr Surg 2004;113:1140-1145.

12. Rohner D, Jaquiery C, Kunz C, Bucher P, Maas H, Hammer B. Maxillofacial reconstruction with prefabricated osseous free flaps: a 3-year experience with 24 patients. Plast Reconstr Surg 2003; 112:748-757.

13. Pogrel MA, Podlesh S, Anthony JP, Alexander J. A comparison of vascularized and nonvascularized bone grafts for reconstruction of mandibular continuity defects. J Oral Maxillofac Surg 1997;55: $1200-1206$.

14. Urken ML, Buchbinder D, Constantino P. Oromandibular reconstruction using microvascular composite flaps. Arch Otolaryngol Head Neck Surg 1998;124:46-55.
15. Vaughan ED, Bainton R. Martin IC. Improvements in morbidity of mouth cancer using microvascular free flap reconstruction. J Craniomaxillofac Surg 1992;20:132-134.

16. Cricchio G, Lundgren S. Donor site morbidity in two different approaches to anterior iliac crest bone harvesting. Clin Implant Dent Relate Res 2003;5:161-169.

17. Cordeiro PG, et al. Conceptual considerations in mandibular reconstruction. Clin Plast Surg 1995;22:61.

18. Fortin Y, Sullivan RM, Rangert BR. The Marius implant bridge: surgical and prosthetic rehabilitation for the completely edentulous upper jaw with moderate to severe resorption: a 5year retrospective clinical study. Clin Implant Dent Relat Res 2002;4:69-77.

19. Cheung LK, Leung AC. Dental implants in reconstructed jaws: implant longevity and peri-implant tissue outcomes. J Oral Maxillofac Surg 2003;61:1263-1274.

20. Brown JS, Jones DC, Summerwill A, Rogers SN, Howell RA, Cawood JI, Vaughan ED. Vascularized iliac crest with internal oblique muscle for immediate reconstruction after maxillectomy. Br J Oral Maxillofac Surg 2002;40:183-190.

21. Hidalgo DA, Rekow A. A review of 60 consecutive fibula free flap mandible reconstruction. Plast Reconstr Surg 1995;96:585-596.

22. Swartz WM, Banis JC, Newton ED, et al. The osteocutaneous scapular flap for mandibular and maxillary reconstruction. Plast Reconstr Surg 1986;77:530-545.

23. Richardson D, Fisher SE, Vaughan DE, Brown JS. Radial forearm flap donor site complications and morbidity: a prospective study. Plast Reconstr Surg 1997;99:109-115. 